\title{
Transcriptome analyses of porcine endometrium during the pre-implantation phase
}

\author{
Stefan Bauersachs
}

Laboratory for Functional Genome Analysis (LAFUGA) and Chair for Molecular Animal Breeding and Biotechnology, Gene Center, LMU Munich, Feodor Lynen Str. 25, 81377 Munich, Germany

The porcine conceptus undergoes rapid differentiation and expansion of its trophoblastic membranes between days 11 and 12 of gestation. The production of estrogen, the porcine embryonic pregnancy recognition signal, by the conceptus increases with trophoblast elongation. A complex interplay of estrogen signaling and prostaglandin (PG) metabolism in the endometrium finally results in prevention of luteolysis. Conceptus attachment to the uterine surface epithelium starts around day 14 of pregnancy preceded by a pronounced vascularization at the implantation zones, initiating the epitheliochorial placentation. To characterize the transcriptome changes in the porcine endometrium in the course of maternal recognition of pregnancy (MRP) and initial placentation, several transcriptome analyses using DNA microarrays and RNA sequencing (RNASeq) have been performed. This review summarizes and compares the results of these studies. Particularly, the studies where RNA-Seq has been used, revealed more than 2,500 and 1,900 differentially expressed genes (DEGs) for days 12 and 14 of pregnancy, respectively, in comparison to corresponding cyclic controls. Analysis of the results of these two studies revealed distinct differential gene expression, reflecting the different functions of the endometrium during these stages. The comparison of RNASeq and microarray data for day 14 of pregnancy revealed a good agreement of the results. Moreover, results of microarray studies investigating local responses of the uterine horn to embryos in the blastocyst stage and effects of premature exposure of pregnant gilts to exogenous estrogen on endometrium during early pregnancy are discussed and compared to the results from day 12 and day 14 of pregnancy.

\section{Introduction}

Establishment of pregnancy in mammals requires prolongation of luteal life span for sustained progesterone (P4) production. P4 stimulates secretory functions of the endometrium required for conceptus development and implantation. Maternal recognition and establishment of pregnancy in pigs requires a biphasic pattern of estrogen (E2) secretion (Geisert et al. 1990). Between days 11 and 12 of gestation, the porcine conceptus undergoes rapid differentiation and expansion of its trophoblastic membranes (Geisert et al. 1982, Stroband \& Van der Lende 1990, Yelich et al. 1997). Coordinate with trophoblastic elongation, conceptus secretion of E2 increases (Ford et al. 1982, Stroband \& Van der Lende 1990). The second phase of increased E2 secretion is between days 15 and 30 of pregnancy. Luteoprotective action of E2 is complex. 
It stimulates luteal P4 secretion directly (Conley \& Ford 1989). However, the basic model is that conceptus estrogen produced between days 11 and 16 elicits a change in the direction of prostaglandin F2 alpha (PGF2a) secretion from endocrine to exocrine resulting in sequestration of PGF2a in the uterine lumen and consequently in prevention of luteolysis (Bazer \& Thatcher 1977). Furthermore, conceptus and endometrial prostaglandin E2 (PGE2) has been shown to influence prostaglandin (PG) metabolism in favor of luteoprotective PGE2 (Waclawik 2011, Ziecik et al. 2011). Endometrial luteoprotective PGE2 and luteolytic PGF2a are involved in reproduction processes in many species (Weems et al. 2006, Kennedy et al. 2007). It has been demonstrated that inhibition of PG synthesis before implantation causes pregnancy failure in different species, including the pig (Kennedy et al. 2007). Before implantation, the endometrium and trophoblast synthesize elevated amounts of PGE2, which results in high amounts of this PG in the uterine lumen and/or utero-ovarian circulation in pigs. It has been shown that expression of enzymes of the PG synthesis pathway is altered in the porcine conceptus and endometrium to favor luteoprotective PGE2 synthesis between days 10 and 13 of pregnancy (Waclawik et al. 2006, Waclawik \& Ziecik 2007).

Epitheliochorial placentation is starting on day 14 of pregnancy, and is associated with specific tissue remodeling at implantation sites, e.g. increased vascularization and vascular permeability at implantation zones and changes in the luminal epithelium (Keys \& King 1988, Keys \& King 1989, Keys \& King 1990). Pigs show a true epitheliochorial placentation since the luminal epithelium remains completely intact throughout pregnancy, (Keys \& King 1988). Several inflammatory mediators including cytokines and growth factors are associated with conceptus growth, implantation and establishment of pregnancy (Croy et al. 2009, Waclawik 2011). Porcine conceptuses and also the endometrium produce interferons (IFN), which do not have antiluteolytic functions (Johnson et al. 2009). The trophectoderm expresses both, type I IFNs (IFN delta, IFND) and type II IFNs (IFN gamma, IFNG) starting from Day 11/12 of pregnancy (Cross \& Roberts 1989, Lefevre et al. 1990) with peak expression of IFND on Day 15, whereas natural killer (NK) cells are the endometrial source of IFNG (Murphy et al. 2009). This results in increased expression of IFN stimulated genes (ISGs) in the stroma and glandular epithelium (GE) which likely have a role in uterine remodeling to support placentation (Johnson et al. 2009). IFNG is thought to be involved in the initiation of endometrial vascular remodeling, angiogenesis at implantation sites and modulation of the maternal immune system (Murphy et al. 2009).

To obtain a systematic overview of gene expression changes in porcine endometrium in during the pre-implantation phase a number of transcriptome studies have been performed. This review summarizes the results of a microarray study on day 6 of pregnancy (Alminana et al. 2012), RNA-Seq studies on days 12 (Samborski et al. 2013, unpublished data) and 14 of pregnancy (Samborski et al. 2013) a microarray study on day 14 of pregnancy (Østrup et al. 2010) and a study of the effects of premature estrogen exposure on gene expression in pregnant endometrium (Ross et al. 2007).

\section{Identification of early local endometrial responses to the presence of blastocysts}

The porcine embryo enters the uterus around day 5 after estrus in the morula stage and reaches the blastocyst stage on day 6 (Rüsse \& Sinowatz 1998). To study the effects of early embryomaternal interactions on endometrial gene expression, Alminana et al. (Alminana et al. 2012) used laparoscopic insemination of one oviduct to obtain samples from the tip of the uterine horn containing either embryos ("pregnant horn") or oocytes ("control horn") from the same sow. Using this model, about 200 genes were identified as differentially expressed in the tip of the 
uterine horn on day 6 of pregnancy, almost all genes with lower expression levels in the uterine horn containing embryos. The authors found a number of genes related to immune functions and postulated the down-regulation of immune-related genes as a mechanism to protect the early embryo from the maternal immune system. However, the analysis of overrepresented functional categories of the down-regulated genes (194 genes could be assigned to putative human orthologous genes) did not show overrepresentation of immune-related genes (Fig. 1). Four genes could be assigned to 'immune response' via SP PIR keywords and 3 genes based on Gene Ontology. A number of other functional categories showing significant overrepresentation were identified, i.e. more genes were found for these categories than expected by chance. The highest overrepresentation was found for a group of categories related to 'vesicle membrane', particularly for 'Golgi-associated vesicle membrane' (Fig. 1). This could indicate an effect of early embryos on specific secretory processes in endometrial cells. Furthermore, functional categories related to the process 'RNA splicing' were found as overrepresented for the genes down-regulated on day 6 of pregnancy. Differential expression of a splicing factor during the cycle has been shown in human and mouse endometrium and suggested to play a role in preparation of a receptive uterus (Nie et al. 2002).

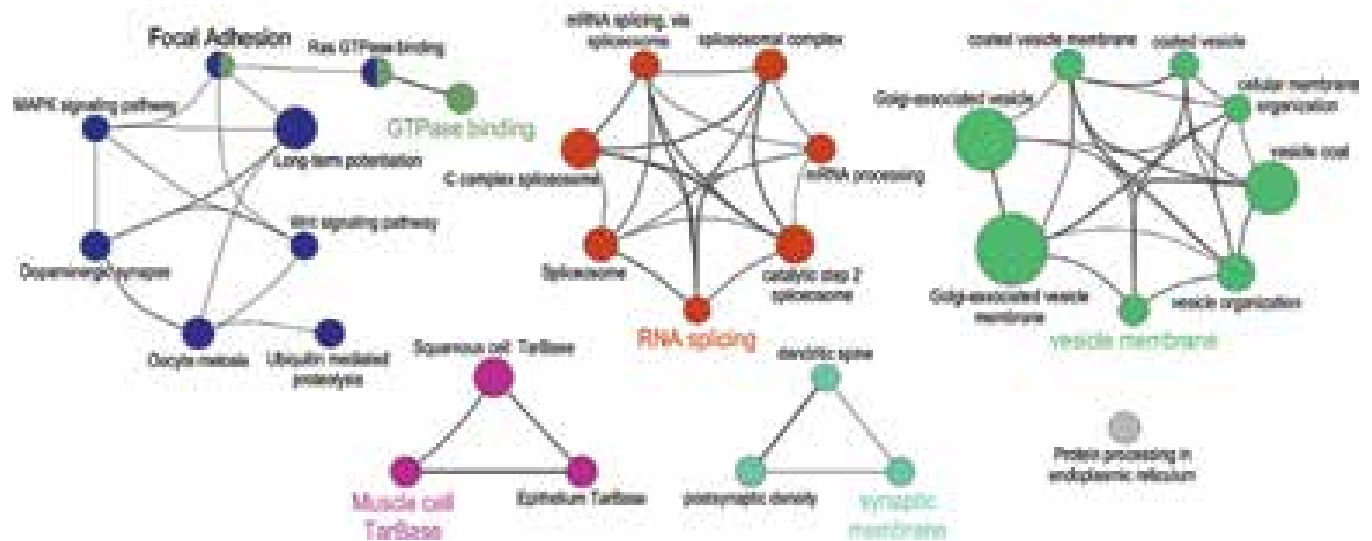

Fig. 1 Network of overrepresented Gene Ontology categories, KEGG and WIKI pathways for genes with lower transcript levels in the uterine horn harboring embryos compared to the control uterine horn without embryos on day 6 of pregnancy after laparoscopic insemination into one oviduct. All significant genes (human Entrez Gene IDs) with lower transcript levels in pregnant endometrium were used as input for the Cytoscape 3.0.0.beta1 application ClueGO 2.0.0.beta1. To limit the search results, the following parameters were used: GO tree levels: 2-15, minimal number of genes: 5, \%genes: 3, p-value correction: 'Benjamini-Hochberg', terms with p-value <0.05, GO term fusion, GO term connection restriction (kappa score): 0.3, GO term grouping: initial group size $=3$ and $50 \%$ for group merge. The resulting network was modified, i.e. redundant and non-informative terms were deleted and the network was manually rearranged. Node size was adjusted relative to \% associated genes. Edge line width was assigned in relation to the kappa score.

\section{Gene expression in porcine endometrium during the pre-implantation phase - RNA-Seq analysis on days 12 and 14 of pregnancy}

Day 12 of pregnancy

In a recent study the response of the porcine endometrium to the presence of filamentous conceptuses on day 12 of pregnancy, the time of maternal recognition of pregnancy, was investigated using RNA sequencing (RNA-Seq) (Samborski et al. 2013, unpublished data). 
This study resulted in the identification of 2,593 differentially expressed genes (DEG) (FDR $1 \%$ ) indicating a complex response to conceptus signals. The search for significantly enriched functional categories for genes with higher mRNA concentration in pregnant endometrium revealed the highest overrepresentation for genes related to cell cycle, cell division and mitosis. Additional clearly overrepresented categories were 'cytoplasmic vesicle', 'metallopeptidase activity', 'apoptosis', and 'blood vessel development'. The genes contained in the latter category could have a role for vascular remodeling in the implantation zones that occurs during increase in conceptus estrogen release (Keys \& King 1988).

For the down-regulated genes, overrepresented functional categories were related to 'intermediate filament', 'keratin filament', 'steroid metabolic process', 'phospholipase activity', 'icosanoid metabolic process', and 'unsaturated fatty acid metabolic process'. Particularly, the category 'intermediate filament' was highly overrepresented with 21 keratin genes and one keratin-associated gene (out of 23 genes in total). Keratins are typical intermediate filament proteins of epithelia and have an important role for the mechanical stability and integrity of epithelial cells. Furthermore, keratins are related to the epithelial type and stage of cellular differentiation (Moll et al. 2008).

The genes found as differentially expressed in the study of day 6 of pregnancy (Alminana et al. 2012) were compared to the DEGs found on day 12 of pregnancy. This revealed 35 genes differentially expressed on day 6 and on day 12 of pregnancy, which is slightly more than expected by chance. However, the overlapping genes were down-regulated on day 6 and upregulated on day 12 , except for two genes.

\section{Day 14 of pregnancy}

To characterize transcriptome changes in the endometrium associated with initial conceptus attachment deep sequencing of endometrial RNA samples was performed (Samborski et al. 2013) on day 14 in comparison of pregnant and corresponding cyclic gilts. This study revealed 1,933 differentially expressed genes (FDR 1\%), 1,229 with higher and 704 with lower mRNA concentration in the samples from pregnant gilts. The comparison of the results to the previous microarray study of day 14 of pregnancy (Østrup et al. 2010) using Gene Set Enrichment Analysis (GSEA) (Subramanian et al. 2005) revealed a good overlap even though different experimental settings and different platforms for gene expression analysis were used (Samborski et al. 2013). Furthermore, a substantial overlap of the day 14 RNA-Seq data set was also found for the comparison to results of a microarray study of bovine endometrium on day 18 of pregnancy and the response of bovine endometrium to IFN alpha (Bauersachs et al. 2012). Most of these genes were known IFN-stimulated genes (ISGs) probably induced by conceptus IFND and IFNG. Correspondingly, bioinformatics analysis revealed for the genes with higher mRNA concentration in day 14 pregnant porcine endometrium strong overrepresentation for immunerelated functional terms, but also for functions related to apoptosis and cell adhesion. For the process of cell adhesion a number of members of the integrin family were found as differentially expressed (Samborski et al. 2013). According to non-invasive placentation in pigs, integrins with functions in cell-cell adhesion were found with higher mRNA concentration in day 14 pregnant porcine endometrium, whereas integrins functioning in cell migration and invasion were found to have lower mRNA concentration in pregnant endometrium. The analysis of the genes with lower mRNA concentration in pregnant endometrium revealed strong overrepresentation of members of the EPH-ephrin system. The EPH-ephrin system has an important function in cell-cell and cell-matrix adhesion and in the regulation of cell migration through interaction with a variety of proteins involved in other signaling pathways such as integrins, claudins, cadherins, and connexins (Arvanitis \& Davy 2008). In porcine endometrium down-regulation 
of the EPH-ephrin system could be a mechanism to control trophoblast attachment and prevent invasion through the endometrial epithelium. An additional process important in the context of placentation is the transport of nutrients and ions. The transport of ions was also highly overrepresented for the down-regulated genes. Most of the identified transporters were related to sodium, potassium and calcium transport (Samborski et al. 2013). Comparing transporter genes of the up-regulated and the down-regulated genes, very different types of transporters with respect to their substrates were obtained, indicating specific regulation by conceptus signals of endometrial secretions according to the requirements of the developing conceptus.

\section{Comparison of differential gene expression on days 12 and 14 of pregnancy}

The comparison of the RNA-Seq results obtained for days 12 and 14 (overlap of DEG pregnant vs. non-pregnant) revealed only a moderate overlap (Samborski et al. 2013, unpublished data). This reflects the different functions of the endometrium during these stages, i.e. recognition of pregnancy on day 12 with the corresponding response to conceptus estrogen and preparation for conceptus implantation on day 14 associated with the response to IFNs. Selected functional categories, which are specifically overrepresented for up-regulated genes either on day 12 or on day 14 are listed in Table 1. On day 12 for example, specific overrepresentation was obtained for genes related to cell division and vasculature development and genes coding for serine/ threonine-protein kinases. Several typical genes related to angiogenesis and vascular remodeling were found such as fms-related tyrosine kinase 1 ( FLT1, alias VEGFR1), kinase insert domain receptor (a type III receptor tyrosine kinase) $(K D R$, alias VEGFR2) placental growth factor (PGF) vascular endothelial growth factor $C$ (VEGFC), angiopoietin 2 (ANGPT2), and TEK tyrosine kinase, endothelial (TEK). Most of the functional categories specifically overrepresented on day 14 were related to immune functions. In addition, specific up- or down-regulation of genes with functions involved in cell adhesion and cell migration was found for day 14 . These genes could play a role in regulation of conceptus attachment and prevention of trophoblast invasion.

Table 1: Comparison of overrepresented Gene Ontology categories between days 12 and 14 of pregnancy for up-regulated genes

\begin{tabular}{|c|c|c|c|c|c|c|}
\hline \multirow[b]{2}{*}{ Functional category } & \multicolumn{3}{|c|}{ Day 12 of pregnancy } & \multicolumn{3}{|c|}{ Day 14 of pregnancy } \\
\hline & Genes & $F E$ & FDR \% & Genes & $F E$ & FDR \% \\
\hline \multicolumn{7}{|l|}{ Specific enrichment on day 12 of pregnancy } \\
\hline cell cycle & 107 & 2.1 & 0.0 & 40 & 0.9 & 100.0 \\
\hline centrosome & 37 & 2.5 & 0.0 & 9 & 0.7 & 100.0 \\
\hline vasculature development & 32 & 1.9 & 1.0 & 21 & 1.4 & 88.8 \\
\hline metallopeptidase activity & 26 & 2.2 & 0.4 & 11 & 1.0 & 100.0 \\
\hline serine/threonine-protein kinase & 46 & 2.0 & 0.0 & 18 & 0.9 & 100.0 \\
\hline \multicolumn{7}{|l|}{ Specific enrichment on day 14 of pregnancy } \\
\hline defense response & 49 & 1.2 & 91.8 & 115 & 3.1 & 0.0 \\
\hline leukocyte activation & 20 & 1.2 & 99.5 & 63 & 4.4 & 0.0 \\
\hline integrin-mediated signaling pathway & 10 & 2.2 & 52.6 & 17 & 4.1 & 0.0 \\
\hline regulation of apoptosis & 70 & 1.3 & 23.6 & 91 & 1.9 & 0.0 \\
\hline chemotaxis & 11 & 1.0 & 100.0 & 30 & 3.1 & 0.0 \\
\hline
\end{tabular}

FE: fold enrichment; FDR: false discovery rate 

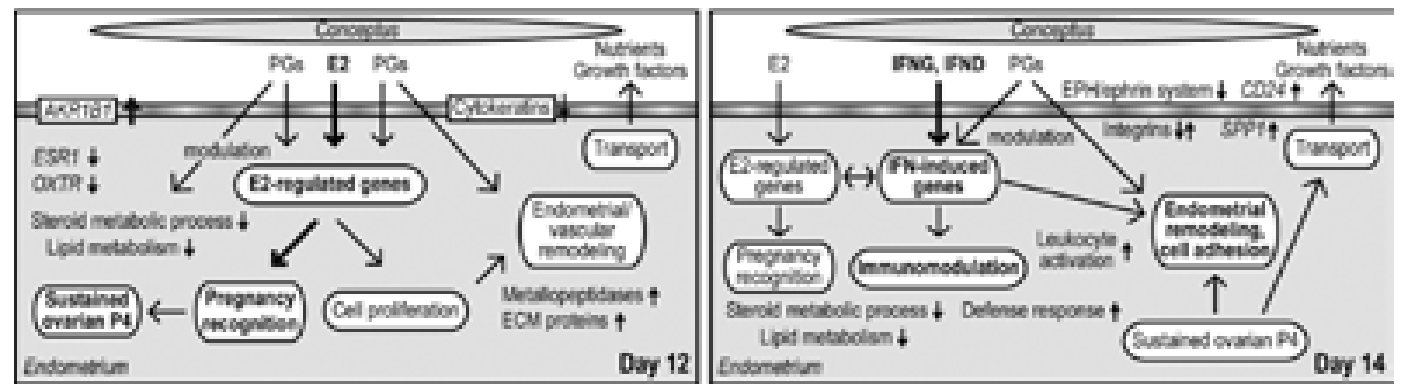

Fig. 2 Schematic overview of important processes on days 12 and 14 of pregnancy deduced from results of transcriptome studies. E2: estradiol, IFNG: interferon gamma, IFND: interferon delta, PGs: prostaglandins, P4: progesterone, ESR 1: estrogen receptor 1 (ER alpha), OXTR: oxytocin receptor, CD24: CD24 molecule, SPP1: secreted phosphoprotein 1 (osteopontin).

A schematic overview of important processes on days 12 and 14 of pregnancy revealed by the transcriptome analyses is shown in Fig. 2.

\section{Expression of genes related to prostaglandin metabolism and signaling}

Prostaglandin metabolism and signaling plays a particular role in recognition of pregnancy, endometrial and conceptus development. A number of genes related to these pathways have been found as differentially expressed during the pre-implantation period. Table 2 shows selected genes found as differentially expressed in porcine endometrium on day 12 and/or on day 14 of pregnancy in comparison to non-pregnant control endometria. The highest fold up-regulation on day 12 was found for aldo-keto reductase family 1, member B1 (aldose reductase) (AKR1B1). First identified as a more general detoxifying enzyme, AKR1B1 has been shown to exert also more specific functions and modifies or generates signal molecules (Pastel et al. 2012). With regard to reproductive functions, AKR1B1 has been shown to function as a highly efficient and physiologically relevant PGF synthase that is expressed during the secretory phase in both epithelial and stromal cells in human endometrium (Bresson et al. 2011). The expression in porcine endometrium was 32-fold higher on day 12 of pregnancy with very high expression levels as indicated by very high read counts found in the RNA-Seq data. Interestingly, AKR 1B1 mRNA expression is also 8-fold lower in day 14 cyclic compared to day 12 cyclic endometrium and decreases 86-fold from day 12 to day 14 of pregnancy, indicating a specific short-term upregulation of $A K R 1 B 1$ that coincides with the time of recognition of pregnancy. Localization of $A K R 1 B 1 \mathrm{mRNA}$ expression in porcine endometrium has been shown in the luminal epithelium on days 12 and 13 of pregnancy (Ross et al. 2007). The highest expression difference for day 14 was found for phospholipase A2, group IID (PLA2G2D) with 53-fold higher mRNA concentration in pregnant compared to cyclic endometrium. Expression was not detectable on day 12. This agrees well with the finding that PLA2G2D expression is induced by IFNG (Lindbom et al. 2002). Most of the genes involved in PG synthesis showed lower mRNA concentrations in day 12 pregnant endometrium, particularly hydroxyprostaglandin dehydrogenase 15-(NAD) (HPGD) and prostaglandin-endoperoxide synthase 2 (prostaglandin $\mathrm{G} / \mathrm{H}$ synthase and cyclooxygenase) (PTGS2). In addition, lower mRNA concentration in pregnant endometrium on day 14 were found for genes involved in the synthesis of unsaturated fatty acids (Samborski et al. 2013). One of the end products of this pathway is arachidonic acid, the precursor for PG synthesis, further suggesting a general down-regulation of the PG synthesis pathway, which could be a general mechanism to regulate PG synthesis and to prevent luteolysis. 
Transcriptomics of porcine endometrium

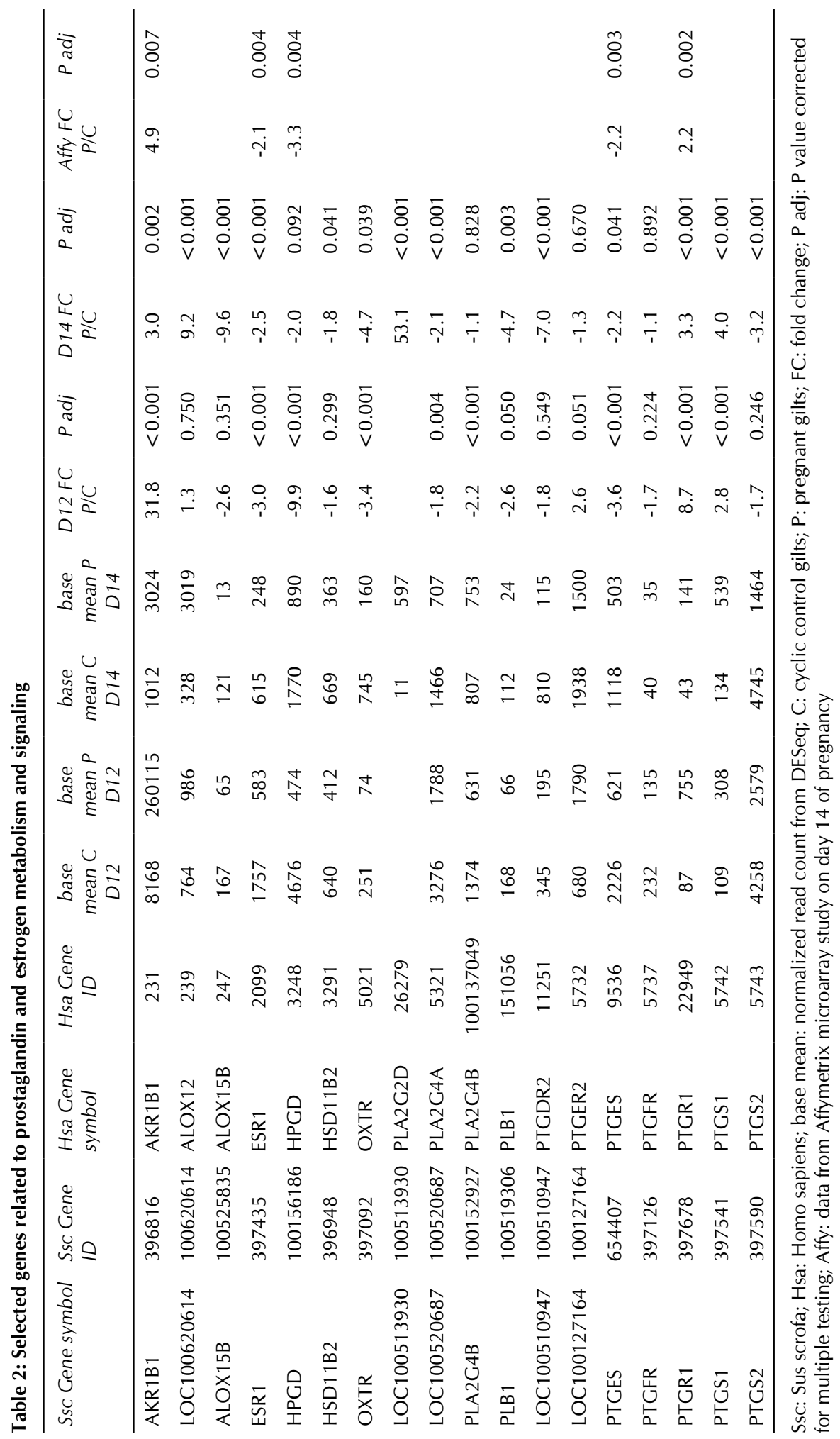




\section{Effects of premature exposure of pregnant gilts to exogenous estrogen on endometrium during early pregnancy}

Premature estrogen exposure disrupts the establishment of a viable pregnancy in pigs since it interferes with conceptus estrogen signaling (Morgan et al. 1987). In a previous microarray study, the effects of premature estrogen exposure to pregnant gilts on endometrial gene expression during the peri-implantation phase have been investigated (Ross et al. 2007). A number of genes were identified to have aberrant expression on days 10, 13 and 15 of pregnancy in comparison of the treatment with estradiol and corn oil as a control on days 9 and 10 of pregnancy. The comparison to the results of our RNA-Seq studies on days 12 and 14 of pregnancy showed, that many of these genes were differentially expressed between pregnant and cyclic endometrium. Genes with at least twofold change between pregnant and cyclic endometrium are listed in Table 3. The gene retinol binding protein 4, plasma (RBP4) was found as up-regulated on day 10 of pregnancy after estrogen treatment on day 9 (8-fold) and on day 12 of pregnancy in comparison to day 12 of the estrous cycle (7-fold). Genetic studies have shown an association of RBP4 gene variants with litter size (Munoz et al. 2010). The expression of 4 genes (AKR1B1, $C D 24, N M B$ and SPP1) was localized to the luminal epithelium suggesting a role in maternalconceptus interaction (Ross et al. 2007). CD24 is normally expressed on mature granulocytes and in many B cells but was also found in decidual stromal cells (Montes et al. 1996). Expression in porcine endometrium on days 12 and 14 of the estrous cycle was very low but increased strikingly on days 12 and 14 of pregnancy (108-fold and 668-fold, respectively, in comparison to corresponding days of the cycle). AKR1B1 expression on day 13 was 14-fold lower after premature estrogen treatment. Together with the specific up-regulation found on day 12 of pregnancy this suggests an important role of $A K R 1 B 1$ for recognition and establishment of pregnancy in the pig. Likewise, for secreted phosphoprotein 1 (osteopontin) (SPP1) a wrong timing of regulation due to estrogen exposure on days 9 and 10 of pregnancy is obvious, with 3.4-fold higher expression on day 13 and 1.9-fold lower expression on day 15 of pregnancy after estrogen treatment, whereas similar expression on days 12 and 14 of the estrous cycle and 5.5-fold higher expression on day 12 and 13-fold higher expression on day 14 of pregnancy was found. Altogether, this comparison revealed a number of genes, which could have a particular role in maternal recognition of pregnancy.

In conclusion, transcriptome studies during the pre- and peri-implantation period revealed a number of new molecular pathways and biological processes associated with and important for recognition of pregnancy and preparation for embryo implantation in the pig. Although these studies have their limitations since endometrial tissue samples have a complex and dynamic composition regarding different endometrial cell types and changes in mRNA concentrations do not always correlate with changes in abundance of the corresponding protein, they can deliver new hypotheses and find new molecular pathways which never have been considered before to be involved in these biological processes.

\section{Declaration of interest and funding}

The author declares that there is no conflict of interest that could be perceived as prejudicing the impartiality of the research reported.

This work has been supported by the German Ministry for Education and Research (BMBF, FUGATO-plus, COMPENDIUM). 
Table 3: Genes with altered expression after premature estrogen exposure to pregnant gilts and differential expression on day 12 and/or on day 14 of pregnancy compared to cyclic controls

\begin{tabular}{|c|c|c|c|c|c|c|c|c|c|c|c|}
\hline $\begin{array}{c}\text { Hsa Entrez } \\
\text { Gene ID }\end{array}$ & $\begin{array}{c}\text { Hsa Gene } \\
\text { symbol }\end{array}$ & $\begin{array}{c}E C / C O \\
F C\end{array}$ & $P$ value & $\begin{array}{c}\text { base } \\
\text { mean } C\end{array}$ & $\begin{array}{c}\text { base } \\
\text { mean } P\end{array}$ & $\begin{array}{c}D 12 \\
F C P / C\end{array}$ & $P$ adj & $\begin{array}{c}\text { base } \\
\text { mean } C\end{array}$ & $\begin{array}{c}\text { base } \\
\text { mean } P\end{array}$ & $\begin{array}{c}D 14 \\
F C P / C\end{array}$ & $P$ adj \\
\hline \multicolumn{12}{|c|}{ D10 after exogenous $E C$ on $d 9$ of gestation } \\
\hline 5950 & RBP4 & 8.3 & 0.028 & 23640 & 173649 & 7.3 & $<0.001$ & 111862 & 199800 & 1.8 & 0.003 \\
\hline \multicolumn{12}{|c|}{ D13 after exogenous $E C$ on $d 9$ and $d 10$ of gestation } \\
\hline 57406 & ABHD6 & 1.9 & 0.083 & 1216 & 4067 & 3.3 & 0.001 & 779 & 2058 & 2.6 & $<0.001$ \\
\hline 199 & AIF1 & -2.4 & 0.100 & 213 & 282 & 1.3 & 0.352 & 102 & 939 & 9.2 & $<0.001$ \\
\hline 231 & AKR1B1 & -13.9 & 0.001 & 8168 & 260115 & 31.8 & $<0.001$ & 1012 & 3024 & 3.0 & 0.002 \\
\hline 307 & ANXA4 & -2.1 & 0.015 & 43908 & 51138 & 1.2 & 0.503 & 10151 & 5003 & -2.0 & $<0.001$ \\
\hline 245973 & ATP6V1C2 & -1.9 & 0.056 & 24315 & 10681 & -2.3 & 0.002 & 4798 & 3371 & -1.4 & 0.674 \\
\hline 79161 & C7orf23 & -3.5 & 0.015 & 5016 & 15860 & 3.2 & $<0.001$ & 2013 & 1461 & -1.4 & 0.156 \\
\hline 100133941 & CD24 & 4.6 & 0.001 & 97 & 10479 & 107.6 & $<0.001$ & 62 & 41726 & 667.7 & $<0.001$ \\
\hline 29126 & CD274 & -4.1 & 0.013 & 16 & 87 & 5.5 & $<0.001$ & 9 & 189 & 20.3 & $<0.001$ \\
\hline 1075 & CTSC & 2.0 & 0.056 & 1835 & 11766 & 6.4 & $<0.001$ & 2946 & 10822 & 3.7 & $<0.001$ \\
\hline 2224 & FDPS & -2.7 & 0.013 & 109960 & 55144 & -2.0 & $<0.001$ & 38788 & 6761 & -5.7 & $<0.001$ \\
\hline 2938 & GSTA1 & 2.0 & 0.019 & 1195 & 518 & -2.3 & 0.327 & 3855 & 1129 & -3.4 & 0.003 \\
\hline 51451 & LCMT1 & 2.3 & 0.062 & 172 & 45 & -3.9 & 0.009 & 38 & 27 & -1.4 & 0.553 \\
\hline 9448 & MAP4K4 & -2.5 & 0.003 & 8015 & 28078 & 3.5 & $<0.001$ & 4468 & 5831 & 1.3 & 0.186 \\
\hline 4233 & MET & -2.3 & 0.006 & 1329 & 5970 & 4.5 & $<0.001$ & 1367 & 960 & -1.4 & 0.378 \\
\hline 10874 & NMU & -2.7 & 0.004 & 52080 & 28756 & -1.8 & 0.097 & 39169 & 1861 & -21.0 & 0.000 \\
\hline 26227 & $\mathrm{PHGDH}$ & -1.8 & 0.016 & 5844 & 3222 & -1.8 & 0.066 & 7154 & 1702 & -4.2 & 0.000 \\
\hline 51316 & PLAC8 & 3.3 & 0.015 & 490 & 460 & -1.1 & 0.905 & 264 & 4281 & 16.2 & 0.000 \\
\hline 5357 & PLS1 & -4.4 & 0.004 & 18270 & 37315 & 2.0 & $<0.001$ & 6243 & 2410 & -2.6 & 0.000 \\
\hline 29968 & PSAT1 & 2.3 & 0.007 & 17963 & 5236 & -3.4 & 0.001 & 5501 & 6899 & 1.3 & 0.533 \\
\hline 25914 & RTTN & 1.8 & 0.072 & 196 & 94 & -2.1 & 0.014 & 94 & 150 & 1.6 & 0.111 \\
\hline 23623 & RUSC1 & -1.8 & 0.089 & 11288 & 4453 & -2.5 & $<0.001$ & 4939 & 2022 & -2.4 & 0.004 \\
\hline 6288 & SAA1 & 2.9 & 0.005 & 70 & 663 & 9.5 & $<0.001$ & 40 & 540 & 13.5 & $<0.001$ \\
\hline 6446 & SGK1 & 2.0 & 0.023 & 6811 & 22148 & 3.3 & 0.006 & 5892 & 10866 & 1.8 & $<0.001$ \\
\hline 6696 & SPP1 & 3.4 & 0.008 & 701 & 3855 & 5.5 & 0.016 & 721 & 9261 & 12.8 & 0.001 \\
\hline 6822 & SULT2A1 & 2.9 & 0.083 & 2099 & 9665 & 4.6 & 0.004 & 2379 & 14420 & 6.1 & $<0.001$ \\
\hline 8875 & VNN2 & -2.0 & 0.018 & 1114 & 4860 & 4.4 & 0.003 & 7811 & 2110 & -3.7 & 0.216 \\
\hline 79971 & WLS & -1.8 & 0.065 & 23483 & 15407 & -1.5 & 0.036 & 10810 & 5428 & -2.0 & $<0.001$ \\
\hline \multicolumn{12}{|c|}{ D15 after exogenous $E C$ on $d 9$ and d 10 of gestation } \\
\hline 203054 & ADCK5 & -1.9 & 0.073 & 15881 & 8348 & -1.9 & $<0.001$ & 9395 & 2810 & -3.3 & $<0.001$ \\
\hline 567 & B2M & -1.9 & 0.064 & 50308 & 55252 & 1.1 & 0.710 & 47584 & 165175 & 3.5 & $<0.001$ \\
\hline 6288 & SAA1 & -2.1 & 0.056 & 70 & 663 & 9.5 & $<0.001$ & 40 & 540 & 13.5 & $<0.001$ \\
\hline 6696 & SPP1 & -1.9 & 0.062 & 701 & 3855 & 5.5 & 0.016 & 721 & 9261 & 12.8 & 0.001 \\
\hline 6772 & STAT1 & -2.1 & 0.064 & 2445 & 7537 & 3.1 & $<0.001$ & 714 & 5019 & 7.0 & $<0.001$ \\
\hline 57169 & ZNFX1 & -1.8 & 0.064 & 5621 & 5108 & -1.1 & 0.691 & 3504 & 15424 & 4.4 & $<0.001$ \\
\hline
\end{tabular}

Hsa: Homo sapiens; EC: estradiol cypionate; CO: corn oil; FC: fold change; base mean: normalized read count from DESeq; C: cyclic control gilts; P: pregnant gilts; P adj: P value corrected for multiple testing 


\section{References}

Alminana C, Heath PR, Wilkinson S, Sanchez-Osorio J, Cuello C, Parrilla I, Gil MA, Vazquez JL, Vazquez JM, Roca J, Martinez EA \& Fazeli A 2012 Early developing pig embryos mediate their own environment in the maternal tract. PLoS One 7 e33625.

Arvanitis D \& Davy A 2008 Eph/ephrin signaling: networks. Genes Dev 22 416-429.

Bauersachs S, Ulbrich SE, Reichenbach HD, Reichenbach M, Buttner M, Meyer HH, Spencer TE, Minten M, Sax G, Winter G \& Wolf E 2012 Comparison of the effects of early pregnancy with human interferon, alpha 2 (IFNA2), on gene expression in bovine endometrium. Biol Reprod 8646.

Bazer FW \& Thatcher WW 1977 Theory of maternal recognition of pregnancy in swine based on estrogen controlled endocrine versus exocrine secretion of prostaglandin F2alpha by the uterine endometrium. Prostaglandins 14 397-400.

Bresson E, Boucher-Kovalik S, Chapdelaine P, Madore E, Harvey N, Laberge PY, Leboeuf M \& Fortier MA 2011 The human aldose reductase AKR1B1 qualifies as the primary prostaglandin $\mathrm{F}$ synthase in the endometrium. J Clin Endocrinol Metab 96 210-219.

Conley AJ \& Ford SP 1989 Direct luteotrophic effect of oestradiol-17 beta on pig corpora lutea. J Reprod Fertil 87 125-131.

Cross JC \& Roberts RM 1989 Porcine conceptuses secrete an interferon during the preattachment period of early pregnancy. Biol Reprod 40 1109-1118.

Croy BA, Wessels JM, Linton NF, van den Heuvel M, Edwards AK \& Tayade C 2009 Cellular and molecular events in early and mid gestation porcine implantation sites: a review. Soc Reprod Fertil Supp/ 66 233-244.

Ford SP, Christenson RK \& Ford JJ 1982 Uterine blood flow and uterine arterial, venous and luminal concentrations of oestrogens on days 11,13 and 15 after oestrus in pregnant and non-pregnant sows. J Reprod Fertil 64 185-190.

Geisert RD, Brookbank JW, Roberts RM \& Bazer FW 1982 Establishment of pregnancy in the pig: II. Cellular remodeling of the porcine blastocyst during elongation on day 12 of pregnancy. Biol Reprod 27 941-955.

Geisert RD, Zavy MT, Moffatt RJ, Blair RM \& Yellin T 1990 Embryonic steroids and the establishment of pregnancy in pigs. J Reprod Fertil Suppl 40 293-305.

Johnson GA, Bazer FW, Burghardt RC, Spencer TE, Wu G \& Bayless KJ 2009 Conceptus-uterus interactions in pigs: endometrial gene expression in response to estrogens and interferons from conceptuses. Soc Reprod Fertil Supp/ 66 321-332.

Kennedy TG, Gillio-Meina C \& Phang SH 2007 Prostaglandins and the initiation of blastocyst implantation and decidualization. Reproduction 134 635-643.

Keys JL \& King GJ 1988 Morphological evidence for increased uterine vascular permeability at the time of embryonic attachment in the pig. Biol Reprod 39 473-487.
Keys JL \& King GJ 1989 Structural changes in the luminal epithelium of the porcine uterus between days 10 and 19 of the estrous cycle. Am J Anat 185 42-57.

Keys JL \& King GJ 1990 Microscopic examination of porcine conceptus-maternal interface between days 10 and 19 of pregnancy. Am J Anat 188 221-238.

Lefevre F, Martinat-Botte F, Guillomot M, Zouari K, Charley B \& La Bonnardiere C 1990 Interferon-gamma gene and protein are spontaneously expressed by the porcine trophectoderm early in gestation. Eur J Immunol 20 2485-2490.

Lindbom J, Ljungman AG, Lindahl M \& Tagesson C 2002 Increased gene expression of novel cytosolic and secretory phospholipase $\mathrm{A}(2)$ types in human airway epithelial cells induced by tumor necrosis factor-alpha and IFN-gamma. J Interferon Cytokine Res 22 947-955.

Moll R, Divo M \& Langbein L 2008 The human keratins: biology and pathology. Histochem Cell Biol 129 705-733.

Montes MJ, Aleman P, Garcia-Tortosa C, Borja C, Ruiz C \& Garcia-Olivares E 1996 Cultured human decidual stromal cells express antigens associated with hematopoietic cells. J Reprod Immunol 30 53-66.

Morgan GL, Geisert RD, Zavy MT \& Fazleabas AT 1987 Development and survival of pig blastocysts after oestrogen administration on day 9 or days 9 and 10 of pregnancy. J Reprod Fertil 80 133-141.

Munoz M, Fernandez AI, Ovilo C, Munoz G, Rodriguez C, Fernandez A, Alves E \& Silio L 2010 Non-additive effects of RBP4, ESR1 and IGF2 polymorphisms on litter size at different parities in a Chinese-European porcine line. Genet Sel Evol 4223.

Murphy SP, Tayade C, Ashkar AA, Hatta K, Zhang J \& Croy BA 2009 Interferon gamma in successful pregnancies. Biol Reprod 80 848-859.

Nie GY, Hampton AL, Fu GQ, Liu YX, Findlay JK \& Salamonsen LA 2002 A potential molecular mechanism for regulating pre-mRNA splicing of implantation-related genes through unique uterine expression of splicing factor SC35 in women and rhesus monkeys. Reproduction 124 209-217.

Østrup E, Bauersachs S, Blum H, Wolf E \& Hyttel P 2010 Differential endometrial gene expression in pregnant and nonpregnant sows. Biol Reprod 83 277-285.

Pastel E, Pointud JC, Volat F, Martinez A \& LefrancoisMartinez AM 2012 Aldo-Keto Reductases 1B in Endocrinology and Metabolism. Front Pharmacol 3148.

Ross JW, Ashworth MD, White FJ, Johnson GA, Ayoubi PJ, DeSilva U, Whitworth KM, Prather RS \& Geisert RD 2007 Premature estrogen exposure alters endometrial gene expression to disrupt pregnancy in the pig. Endocrinology 148 4761-4773.

Rüsse I \& Sinowatz F 1998 Lehrbuch der Embryologie der Haustiere, 2. Auflage: Verlag Paul Parey, Berlin.

Samborski A, Graf A, Krebs S, Kessler B \& Bauersachs S 2013 Deep Sequencing of the Porcine Endometrial Transcriptome on Day 14 of Pregnancy. Biol Reprod 8884. 
Stroband HW \& Van der Lende T 1990 Embryonic and uterine development during early pregnancy in pigs. J Reprod Fertil Suppl 40 261-277.

Subramanian A, Tamayo P, Mootha VK, Mukherjee S, Ebert BL, Gillette MA, Paulovich A, Pomeroy SL, Golub TR, Lander ES \& Mesirov JP 2005 Gene set enrichment analysis: a knowledge-based approach for interpreting genome-wide expression profiles. Proc Natl Acad Sci U S A 102 15545-15550.

Waclawik A 2011 Novel insights into the mechanisms of pregnancy establishment: regulation of prostaglandin synthesis and signaling in the pig. Reproduction 142 389-399.

Waclawik A, Rivero-Muller A, Blitek A, Kaczmarek MM, Brokken LJ, Watanabe K, Rahman NA \& Ziecik AJ 2006 Molecular cloning and spatiotemporal expression of prostaglandin $\mathrm{F}$ synthase and microsomal prostaglandin E synthase-1 in porcine endometrium. Endocrinology 147 210-221.

Waclawik A \& Ziecik AJ 2007 Differential expression of prostaglandin (PG) synthesis enzymes in conceptus during peri-implantation period and endometrial expression of carbonyl reductase/PG 9-ketoreductase in the pig. J Endocrinol 194 499-510.

Weems CW, Weems YS \& Randel RD 2006 Prostaglandins and reproduction in female farm animals. Vet / $\mathbf{1 7 1}$ 206-228.

Yelich JV, Pomp D \& Geisert RD 1997 Ontogeny of elongation and gene expression in the early developing porcine conceptus. Biol Reprod 57 1256-1265.

Ziecik AJ, Waclawik A, Kaczmarek MM, Blitek A, Jalali BM \& Andronowska A 2011 Mechanisms for the establishment of pregnancy in the pig. Reproduction in domestic animals = Zuchthygiene 46 Suppl 3 31-41. 
